\title{
Prevalence of the Different Types of Palmar Creases Among Medical and Dental Students in Addis Ababa, Ethiopia
}

\section{Mekbeb Afework ${ }^{*}$}

\section{OPEN ACCESS}

Citation: Mekbeb Afework. Prevalence of the Different Types of Palmar Creases Among Medical and Dental Students in Addis Ababa, Ethiopia. Ethiop J Health Sci. 2019;29(3):391

doi:http://dx.doi.org/10.4314/ ejhs.v29i3.12

Received: December 24, 2018

Accepted: February 12, 2019

Published: May 1, 2019

Copyright: (C) 2019 Mekbeb Afework, This is an open access article distributed under the terms of the Creative Commons Attribution License, which permits unrestricted use, distribution, and reproduction in any medium, provided the original author and source are credited.

Funding: Nil

Competing Interests: The authors declare that this manuscript was approved by all authors in its form and that no competing interest exists.

Affiliation and Correspondence:

${ }^{1}$ Department of Anatomy, School of Medicine, College of Health Sciences, Addis Ababa University

*Email: m.afework@yahoo.com; mekbebaf@gmail.com

\author{
ABSTRACT
}

BACKGROUND: Studies have suggested that identification of aberrant palmar creases may give clues for an early and noninvasive method of diagnosis of certain disease conditions. Toward this purpose, awareness of the normal variants of palmar creases must be first recognized. Accordingly, this study aimed to investigate the patterns of palmar creases in healthy Ethiopian population among Medical and Dental Students in Addis Ababa.

SUBJECTS AND METHODS: Right and left palm pictures from 318 (177 females and 141 males) participants were taken using a mobile camera, and evaluated qualitatively. Observations were analyzed by Fisher's exact test, and significance levels for comparisons were set at $p<0.05$.

RESULTS: Aberrant creases were observed in $13.8 \%$ of the palms. Simian crease was the most common among the aberrant crease types, followed by Suwon and Sydney. Palmar creases with two and three points of origin were significantly more common, respectively, in males and the females. Minor variants as accessory to the radial longitudinal crease and middle longitudinal crease were also observed.

CONCLUSION: This study suggests that aberrant crease types at the observed frequencies may not be indicative of known disease conditions as they occurred in apparently healthy Ethiopians. However, the results of this study, besides revealing the patterns of palmar creases among Ethiopians, could give a baseline for studies aimed at diagnosis of disease conditions based on palmar crease configurations. Further qualitative and quantitative studies of palmar creases in wider populations with various conditions, including ethno-geographic factors, are recommended.

KEYWORDS: Palmar crease, Simian crease, Sydney crease, Suwon crease

\section{INTRODUCTION}

Palmar creases are epidermal flexure lines present on palmar surface of the hands. Normally, there are three major or primary palmar creases named radial longitudinal crease (RLC), proximal transverse crease (PTC) and distal transverse crease (DTC) (1).The RLC begins from, with or slightly below the PTC at the radial border of the palm over the metacarpophalangeal joint of the index finger and runs proximally toward the wrist curving laterally. The PTC begins at the 
radial side of the palm and runs medially slightly curving proximally to terminate at the medial border of the hypothenar eminence. The DTC begins proximal to the interdigital space between the index and middle fingers and runs to the ulnar side of the palm, showing a slight distal ward concavity. Normally, both the PTC and DTC do not span the entire width of the palm (2). Several additional minor creases may also present over the palm (1).

According to the manner of origins of the three primary creases on the radial side of the palm, creases are classified into one, two or three points of origin $(3,4)$. Furthermore, variants of each of the three major creases may occur as branched, forked, broken (with detached parts) or cascade (several broken parts that run in a closely overlapping manner), and accompanied by accessory crease which is parallel and more than half the length of the parent crease (5).

Based on the relationships between PTC and DTC, palmar creases are classified into Simian, Sydney and Suwon creases. The Simian crease is a single transverse crease formed by the fusion of PTC and DTC and extends the entire width of the palm (1). It looks like the palmar crease of nonhuman primate animals. The Sydney crease represents a very long version of the PTC, which crosses the whole width of the palm, while the DTC appears normal (6). It was first described and named in Sydney, Australia (6). The Suwon crease, first identified in Suwon, Korea (5), has a crease that extends across the entire width of the palm which is formed by the fusion of PTC and DTC, or as an extended version of distal transverse crease, with an accessory proximal transverse crease.

The patterns of palmar creases are established during the embryonic and early fetal periods and remain unchanged thereafter $(7,8)$. It is determined by the interactions of genetic and environmental factors (9). As the result, various genetic abnormalities and teratogens can affect the patterns of palmar creases. It is thus speculated that deviations in the configurations of palmar creases could be indicative of insults during early intrauterine development. Numerous studies have also indicated associations of aberrant patterns of palmar creases with different disease conditions suggesting for a polygenic inheritance manner, the same as the Dermatoglyphic features (10). Such described abnormalities which are associated with aberrant epidermal creases, in particular Simian and/or Sydney creases, include: Turner's syndrome $(9,11)$, Down's syndrome (12), Cri du-chat syndrome (13), congenital deafness (14), mental retardation (15), hyperactivity (16), fetal alcoholic syndrome (17) and low birth weight (8). In relation to this, palmar crease analysis has been suggested as a valuable tool which could be employed in the early prediction of various congenital anomalies $(5,9,18)$. The use of palmar creases for such purpose is practically convenient as they can be analyzed quickly and easily, and are cheaper (19). However, for such endeavor and for the identification of abnormal palmar crease patterns, the normal variants must be first recognized. Although many studies on palmar crease patterns have been conducted in different parts of the world, there are only limited studies carried out so far in Africa (20-23), and nothing in Ethiopia. African populations are more genetically diverse than nonAfrican populations $(24,25)$. There is also evidence from genetic studies for migration of Semitic speaking people from Arabia into Ethiopia $(26,27)$. It is not known if such genetic diversity in Ethiopian populations may be reflected on their patterns of palm creases. This study is, therefore, aimed to investigate the pattern of palmar creases in a population among healthy Ethiopian volunteers of Medical and Dental students. The findings from this study, besides revealing the patterns of palm creases of Ethiopian population, could be used as a baseline for further studies toward the determination of aberrant palmar crease patterns, which could give clues for an early detection of any possibility of congenital anomalies in quicker, easier, and cheaper manner during perinatal examination.

\section{SUBJECTS AND METHODS}

Sampling technique: Systematic random sampling method was used for recruiting volunteers among students at five medical and dental colleges in Addis Ababa. All eligible volunteers irrespective of age, gender, and ethnicity were included. Subjects who did not agree to participate in the study and

DOI: http://dx.doi.org/10.4314/ejhs.v29i3.12 
those with abnormal palm were excluded from the study.

Source population: The source population was all students of Doctor of Medicine and Doctor of Dental Medicine programs in public and private Colleges in Addis Ababa, Ethiopia. These included School of Medicine of Addis Ababa University (public), and Africa, Bethel, Hayat and Sante Medical Colleges (private).

Sample size determination: The sample size was determined using the one population formula (28). At $95 \%$ level of confidence, expected prevalence of $15.6 \%$ variants (5), $4 \%$ precision, and addition of a $10 \%$ non-responding rate, 327 participants were needed. First year students were randomly selected, and systematic random sampling was used for recruiting every other student in the list. A total of 318 students, comprising of 177 females and 141 males, aged 17-32 years were included in the study, while 9 students failed to respond.

Data collection: The study was conducted during the months of June to August, 2018. Right and left palm pictures were obtained using HTC One M9 mobile camera with $20 \mathrm{mp}$ resolution in accordance with the study and recommendation by Stelin Wersely et al. (29). Pictures were printed on A4 plain papers onto which age and sex of the participants, and sides of the palms were recorded. For purpose of confidentiality, identifying codes were used to keep participants' privacy. Based on the relationships between the PTC and DTC, palmar creases were identified as Simian, Sydney, and Suwon creases. According to the manner of origins of the three primary creases on the radial side of the palm, creases were classified into one, two or three points of origin $(3,4)$. Furthermore, each of the three major creases was studied in detail for any variants and was classified according to Park et al.(5) as: branched, forked, accessory, broken or cascade. Identifications of palmar creases were done on both right and left hands. The levels of symmetry of the creases on both hands were also assessed.

Statistical analysis: Data entry and statistical analysis were performed using, respectively SPSS (version 23) and Open Epi (version 3.01) statistical softwares. Fisher's exact test was used to analyze significance levels at $\mathrm{p}<0.05$.

Ethical consideration: Ethical clearance was obtained from Institutional Review Board of the College of Health Sciences, Addis Ababa University. Prior to the study, informed consent statement was fully explained and a written consent was obtained. Participants were properly informed about the objectives, relevance, and purpose of the study, and assured about the confidentiality of the data.

\section{RESULTS}

Various types of non-variant and aberrant palmar creases were observed (Figure1). Out of the total of 636 palms studied from 177 females and 141 males, aberrant types of creases were seen on 88 (13.8\%) palms (Table 1). Simian crease was the most frequent aberrant crease type detected on 40 $(6.3 \%)$ palms, followed by Suwon and Sydney, which were found respectively on $26(4.1 \%)$ and 22 $(3.5 \%)$ palms. Although the frequencies of the aberrant palmar creases differed between females and males, as well as the two sides; none of these was significant at $\mathrm{P}<0.05$. 

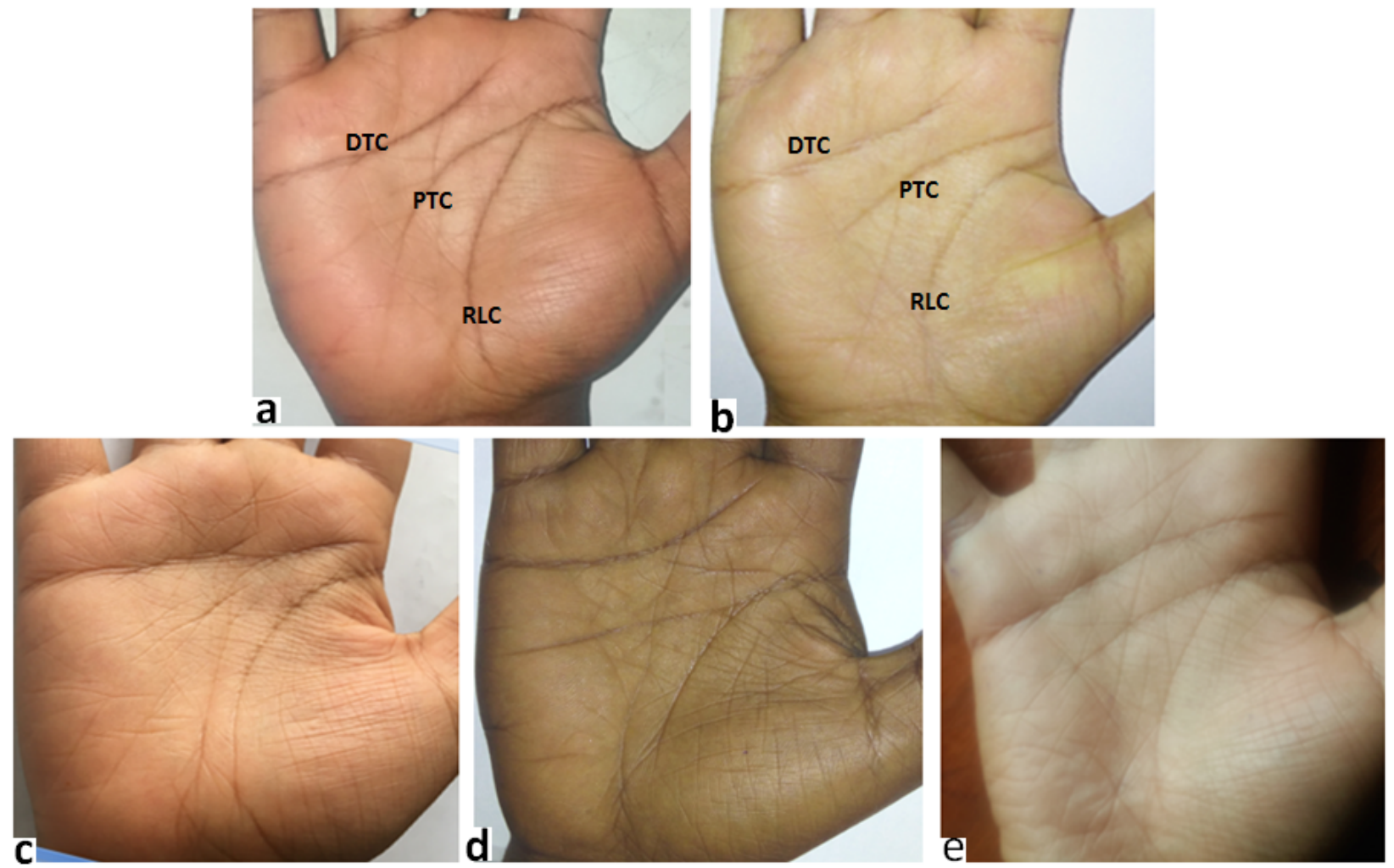

Figure 1: Types of Palm Creases based on the relationship between proximal and distal transverse creases. $a \& b$ : Non-variant creases with 2 points of origin (a) and 3 points of origin (b). c: Simian crease, PTC and DTC have fused and spans the entire width of the palm; $d$ : Sydney crease, PTC crosses the entire width of the palm to near the ulnar border; e: Suwon crease, an extended DTC that spans the entire width of the palm. DTC: distal longitudinal crease; PTC: proximal longitudinal crease; RLC: radial longitudinal crease

Table 1: Incidence of the different types of palmar crease according to sex, side, and laterality

\begin{tabular}{cccccccc}
\hline \multirow{2}{*}{ Type of Crease } & \multirow{2}{*}{ Total } & \multicolumn{2}{c}{ Bilateral } & \multicolumn{3}{c}{ Right } & Lnilateral \\
\hline & F \& M & F & M & F & M & F & M \\
\hline Non-variant & $548(86.2)$ & $139(78.5)$ & $113(80.1)$ & $12(6.8)$ & $8(5.7)$ & $13(7.3)$ & $11(7.8)$ \\
Simian & $40(6.3)$ & $6(3.4)$ & $5(3.5)$ & $4(2.3)$ & $4(2.8)$ & $7(3.9)$ & $3(2.1)$ \\
Sydney & $22(3.5)$ & $3(1.7)$ & $1(0.7)$ & $6(3.4)$ & $4(2.8)$ & $2(1.1)$ & $2(1.4)$ \\
Suwon & $26(4.1)$ & $4(2.3)$ & $1(0.7)$ & $3(1.7)$ & $5(3.5)$ & $3(1.7)$ & $5(3.5)$ \\
Total Aberrant & $88(13.8)$ & $13(7.3)$ & $7(5.0)$ & $13(7.3)$ & $13(9.2)$ & $12(6.8)$ & $10(7.1)$ \\
Total & $636(100.0)$ & $152(85.8)$ & $120(85.1)$ & $25(14.1)$ & $21(14.9)$ & $25(14.1)$ & $21(14.9)$ \\
\hline
\end{tabular}

Values under brackets are percentiles. F: Female; M: Male

With regard to laterality, $13(7.3 \%)$ and $7(5.0 \%)$ of the females and males, respectively, had similar aberrant palmar creases bilaterally. On the other hand, 25(14.1\%) and 23(16.3\%) palms, respectively, from females and males had unilateral aberrant creases. Overall, more frequent unilateral aberrant palmar creases were seen on the right than the left palms, although this was not statistically significant.

No association among the different aberrant palmar creases was observed. All participants with unilateral aberrant palmar creases, except two

DOI: http://dx.doi.org/10.4314/ejhs.v29i3.12 
males, had non-variant crease on their other palms. Only one male had Simian on the right and Suwon on the left, while another one had Suwon on the right and Simian on the left palms.

Palmar creases with two points of origin were the most frequent type observed, followed by three and one points of origin in both females and males, as well as right and left sides (Table 2).
Two points of origin were significantly more frequent on the males' palms, 240(85.1\%), compared to those of the females', 252(71.2\%). On the other hand, females' palm showed significantly more creases with three points of origin, $92(26.0 \%)$, compared to those from the males $34(12.1 \%)$.

Table 2: Incidence of points of origin of palm crease according to sex, side and laterality

\begin{tabular}{cccccccc}
\hline $\begin{array}{c}\text { Points of } \\
\text { Origin }\end{array}$ & Total & \multicolumn{2}{c}{ Bilateral } & \multicolumn{2}{c}{ Right } & Unilateral & Left \\
\hline & F \& M & F & M & F & M & F & M \\
\hline One & $18(2.8)$ & $3(1.7)$ & $3(2.1)$ & $1(0.6)$ & $0(0.0)$ & $3(1.7)$ & $2(1.4)$ \\
Two & $492(77.4)$ & $108^{*}(61.0)$ & $111^{*}(78.7)$ & $10^{\dagger}(5.6)$ & $9(6.4)$ & $26^{* \dagger}(14.7)$ & $9^{*}(6.4)$ \\
Three & $126(19.8)$ & $29^{*}(16.4)$ & $9^{*}(6.4)$ & $26^{* \dagger}(14.7)$ & $9^{*}(6.4)$ & $8^{\dagger}(4.5)$ & $7(5.0)$ \\
Total & $636(100.0)$ & $140(79.1)$ & $123(87.2)$ & $37(20.9)$ & $18(12.8)$ & $37(20.9)$ & $18(12.8)$ \\
\hline
\end{tabular}

Values under brackets are percentiles. F: Female; M: Male; * indicates significant between females and males at $\mathrm{P}<$ 0.05 ; †indicates significant between right and left sides at $\mathrm{P}<0.05$

Overall, $140(79.1 \%)$ females and 123(87.2\%) males were found to have palmar creases with symmetrical bilateral points of origin (Table 2). Palmar creases with two points of origin were significantly more common bilaterally in the males', and unilaterally in the females' left palms. On the other hand, palmar creases with three points of origin were significantly more prevalent in the females bilaterally as well as on the right palms unilaterally. All participants, except one, whose palms showed unilateral one or three points of origin, had two points of origin on their other palms. Only one female with one point of origin on the left palm had three points of origin on the right palm.

Two points of origin were seen in the majority of all types of palmar creases, both nonvariant and aberrant, except for male palms with Simian and female palms with Sydney creases (Table 3). On the contrary, one point of origin occurred only in the Simian crease type.

Table 3: Incidence of points of origin of palm crease according to sex, side, and crease type

\begin{tabular}{cccccccccc}
\hline Sides & $\begin{array}{l}\text { Points } \\
\text { of } \\
\text { Origin }\end{array}$ & \multicolumn{2}{c}{ Non-variant } & \multicolumn{2}{c}{ Simian } & \multicolumn{2}{c}{ Sydney } & \multicolumn{2}{c}{ Suwon } \\
& One & $0(0.0)$ & $0(0.0)$ & $4(2.3)$ & $3(2.1)$ & $0(0.0)$ & $0(0.0)$ & $0(0.0)$ & $0(0.0)$ \\
Right & Two & $101^{*}(57.1)$ & $105^{*}(74.5)$ & $6(3.4)$ & $6(4.3)$ & $5(2.8)$ & $4(2.8)$ & $6(3.4)$ & $5(3.5)$ \\
Palm & Three & $50^{*}(28.2)$ & $16^{*}(11.3)$ & $0(0.0)$ & $0(0.0)$ & $4(2.3)$ & $1(0.7)$ & $1(0.6)$ & $1(0.7)$ \\
& Total & $151(85.3)$ & $121(85.8)$ & $10(5.6)$ & $9(6.4)$ & $9(5.1)$ & $5(3.5)$ & $7(3.9)$ & $6(4.2)$ \\
& One & $0(0.0)$ & $0(0.0)$ & $6(3.4)$ & $5(3.5)$ & $0(0.0)$ & $0(0.0)$ & $0(0.0)$ & $0(0.0)$. \\
Left & Two & $118(66.7)$ & $108(76.6)$ & $7(3.9)$ & $3(2.1)$ & $2(1.1)$ & $3(2.1)$ & $7(3.9)$ & $6(4.2)$ \\
Palm & Three & $34(19.2)$ & $16(11.3)$ & $0(0.0)$ & $0(0.0)$ & $3(1.7)$ & $0(0.0)$ & $0(0.0)$ & $0(0.0)$ \\
& Total & $152(85.9)$ & $124(87.9)$ & $13(7.3)$ & $8(5.7)$ & $5(2.8)$ & $3(2.1)$ & $7(3.9)$ & $6(4.2)$ \\
\hline
\end{tabular}

Values under brackets are percentiles. F: Female; M: Male; * indicates significant between females and males at $\mathrm{P}<$ 0.05

DOI: http://dx.doi.org/10.4314/ejhs.v29i3.12 
In some of the participants, the major palmar creases had variable types of variants (Figure 2). The RLC had relatively the highest frequencies of variants 219 (34.4\%) compared to PTC 97 (15.2\%) or DTC 79 (12.4\%). Among the RLC, accessory crease was the most frequently observed additional variant crease in both sexes (Table 4). This was more frequent (significantly in the females but non-significantly in the males) on the right compared to the left palms. The most frequent variant crease types in the PTC and DTC were, respectively, branched and cascade (Tables 4). Among the DTC, cascade variant was nonsignificantly more prevalent on the left than the right sides.
A minor crease variant, which was described as middle finger crease $(1,21)$, was seen running longitudinally from the region of the wrist toward the metacarpophalangeal joint of the middle finger crossing the PTC and DTC (Figure 2). It occurred with an overall prevalence of $58(9.1 \%)$, more unilaterally. Bilaterally, it was seen on $5(2.8 \%)$ and $4(2.8 \%)$ female and male palms, respectively. It was significantly more prevalent on the right than the left palms, respectively, with values of 17 $(9.6 \%)$ females' and $15(10.6 \%)$ male' palms compared to $3(1.7 \%)$ females' and $5(3.5 \%)$ males' palms.
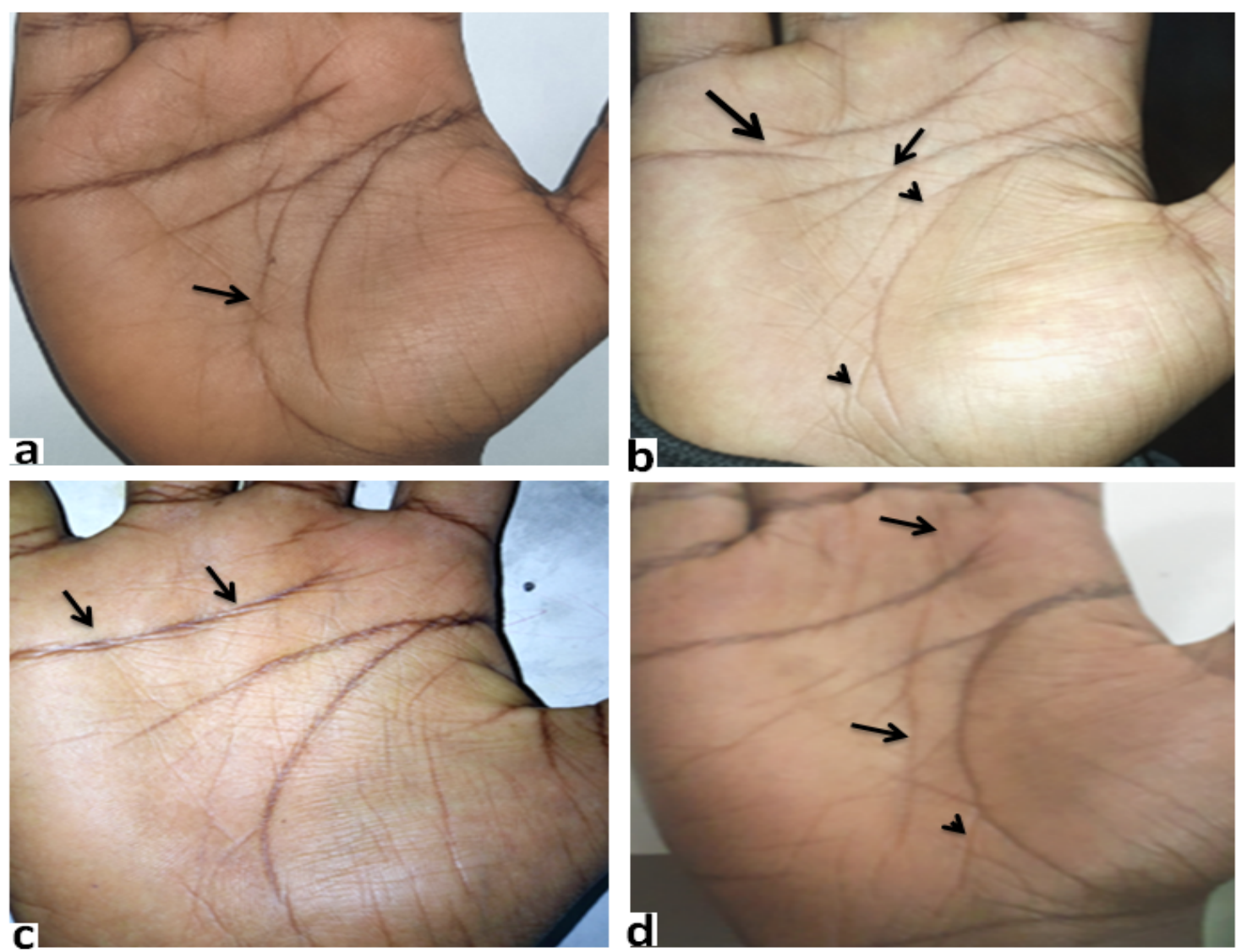

Figure 2: Variants of Palm Creases: Arrow in "a" shows accessory crease of the RLC. In " $b$ " big and small arrows show, respectively broken DTC and forked PTC, while arrow heads show branches of RLC; c: cascade of DTC (arrows); d: middle finger crease (arrows) and branched RLC (arrow head); DTC: distal longitudinal crease; PTC: proximal longitudinal crease; $R L C$ : radial longitudinal crease

Table 4: Incidence of the variants of the major palm creases according to sex, side, and laterality 


\begin{tabular}{|c|c|c|c|c|c|c|c|c|}
\hline \multirow{3}{*}{$\begin{array}{l}\text { Major } \\
\text { Palm } \\
\text { Creases }\end{array}$} & \multirow{3}{*}{ Variants } & \multirow{3}{*}{$\begin{array}{c}\text { Total } \\
\text { F \& M }\end{array}$} & \multirow{2}{*}{\multicolumn{2}{|c|}{$\begin{array}{c}\text { Bilateral } \\
\text { Right \& Left }\end{array}$}} & \multicolumn{4}{|c|}{ Unilateral } \\
\hline & & & & & & & & \\
\hline & & & $\mathbf{F}$ & M & $\mathbf{F}$ & M & $\mathbf{F}$ & M \\
\hline \multirow{7}{*}{ RLC } & Branched & $52(8.2)$ & $9(5.1)$ & $5(3.5)$ & $7(3.9)$ & $4(2.8)$ & $6(3.4)$ & $7(5.0)$ \\
\hline & Forked & $46(7.2)$ & $3(1.7)$ & $8(5.7)$ & $4(2.3)$ & $6(4.3)$ & $7(3.9)$ & $7(5.0)$ \\
\hline & Accessory & $96(15.1)$ & $11(6.2)$ & $10(7.1)$ & $22^{*}(12.4)$ & $13(9.2)$ & $10^{*}(5.6)$ & $9(6.4)$ \\
\hline & Broken & $0(0.0)$ & $0(0.0)$ & $0(0.0)$ & $0(0.0)$ & $0(0.0)$ & $0(0.0)$ & $0(0.0)$ \\
\hline & Cascade & $25(3.9)$ & $0(0.0)$ & $0(0.0)$ & $8(4.5)$ & $5(3.5)$ & $8(4.5)$ & $4(2.8)$ \\
\hline & Non-variant & 417 (65.6) & $94(53.1)$ & $72(51.1)$ & 19 (10.7) & $18(12.8)$ & $29(16.4)$ & $19(13.5)$ \\
\hline & Total & $636(100.0)$ & $117(66.1)$ & 95 (67.4) & $60(33.9)$ & $46(32.6)$ & $60(33.9)$ & $46(32.6)$ \\
\hline \multirow{7}{*}{ PTC } & Branched & $58(9.1)$ & $9(5.1)$ & $6(4.3)$ & $8(4.5)$ & $4(2.8)$ & $9(5.1)$ & $8(5.7)$ \\
\hline & Forked & $22(3.5)$ & $0(0.0)$ & $1(0.7)$ & $2(1.1)$ & $3(2.1)$ & $4(2.3)$ & $11(7.8)$ \\
\hline & Accessory & $4(0.6)$ & $0(0.0)$ & $0(0.0)$ & $1(0.6)$ & $1(0.7)$ & $2(1.1)$ & $0(0.0)$ \\
\hline & Broken & $7(1.1)$ & $0(0.0)$ & $1(0.7)$ & $0(0.0)$ & $2(1.4)$ & $2(1.1)$ & $1(0.7)$ \\
\hline & Cascade & $6(0.9)$ & $1(0.6)$ & $0(0.0)$ & $1(0.6)$ & $0(0.0)$ & $2(1.1)$ & $0(0.0)$ \\
\hline & Non-variant & $539(84.7)$ & $137(77.4)$ & $104(73.8)$ & $18(10.2)$ & $19(13.5)$ & $11(6.2)$ & $9(6.4)$ \\
\hline & Total & $636(100.0)$ & $147(83.0)$ & $112(79.4)$ & $30(16.9)$ & $29(20.6)$ & $30(16.9)$ & $29(20.6)$ \\
\hline \multirow{7}{*}{ DTC } & Branched & $19(3.0)$ & $3(1.7)$ & $1(0.7)$ & $2(1.1)$ & $2(1.4)$ & $3(1.7)$ & $4(2.8)$ \\
\hline & Forked & $21(3,3)$ & $2(1.1)$ & $1(0.7)$ & $3(1.7)$ & $4(2.8)$ & $5(2.8)$ & $3(2.1)$ \\
\hline & Accessory & $3(0.5)$ & $0(0.0)$ & $1(0.7)$ & $0(0.0)$ & $0(0.0)$ & $0(0.0)$ & $1(0.7)$ \\
\hline & Broken & $6(0.9)$ & $0(0.0)$ & $0(0.0)$ & $1(0.6)$ & $4(2.8)$ & $1(0.6)$ & $0(0.0)$ \\
\hline & Cascade & $30(4.7)$ & $6(3.4)$ & $2(1.4)$ & $1(0.6)$ & $3(2.1)$ & $4(2.3)$ & $6(4.3)$ \\
\hline & Non-variant & $557(87,6)$ & $148(83.6)$ & $114(80.9)$ & $2(6.2)$ & $9(6.4)$ & $5(2.8)$ & $8(5.7)$ \\
\hline & Total & $636(100.0)$ & $159(89.8)$ & $119(84.4)$ & $18(10.2)$ & $22(15.6)$ & $18(10.2)$ & $22(15.6)$ \\
\hline
\end{tabular}

Values under brackets are percentiles. F: Female; M: Male; * indicates significant between right and left sides at $\mathrm{P}<$ 0.05

\section{DISCUSSION}

Incidence of the aberrant palmar creases described as Simian, Sydney and Suwon creases show remarkable variations among different studies carried out on different populations. Among the aberrant palmar creases observed in this study, Simian crease was the most frequent. This is consistent with reports by other authors $(5,20,30)$. This value for Simian crease as $6.3 \%$ is relatively closer and between those of the Jews (4.6\%) and the Arabs \& Berbers (7.9\%) and Hausas of Northern Nigeria (8\%), reported previously $(23,31)$. It is, however, more and less than several other studies in various populations with variable figures ranging from $1.2 \%$ in the Swiss to $34.7 \%$ in the Pygmies $(5,20,30,31)$.
Overall, bilateral occurrence of Simian crease was slightly more frequent than unilateral occurrence, and was most frequent on the female left palms. These are different from a previous study report from Central India (30) where unilateral occurrence was slightly greater than bilateral occurrence, with more frequent on the male right palms.

The other aberrant palmar creases observed in this study were Suwon (4.1\%) followed by Sydney (3.5\%) types with slight unilateral preponderances. Sydney crease occurred more frequently on the female right palms, while Suwon crease occurred more in the males with no side difference. These are in line with previous study reports where Suwon crease was more common in males (30), while Sydney crease was more frequent in females $(30,32)$. No association among

DOI: http://dx.doi.org/10.4314/ejhs.v29i3.12 
the different aberrant creases was observed, except for two subjects who had Simian on one palm and Suwon on the other. This is partly in line with the study by Sharma and Sharma (30) in India who have reported three subjects with Simian crease on one hand and Suwon crease on the other hand.

The variable correlations in the values of the different aberrant creases with those of other studies is not surprising as previous studies also presented unpredictable figures among different populations $(26,28-30)$. This could be because of several reasons including ethno-geographic factors and different population sampling. The ethnogeographic factor may be important in this study in light with the presumed relatively more diverse genetic make-up in the Ethiopians than other populations $(26,27)$. This study involved normal individuals engaged in Medical or Dental education who are apparently healthy and relatively intelligent as they were able to join these programs competitively based on similar criteria of better performance in the national examination. As a result, they are relatively homogeneous across the years. Moreover, because palm crease patterns are determined during embryonic and fetal period and remain unchanged, regardless of age $(7,8)$, the findings from the randomly sampled year one students could reflect the patterns of palm creases in the whole students' population. Concomitantly, the incidence of the aberrant palmar creases in the observed frequencies may not necessarily indicate abnormalities. In line with this, aberrant palmar creases, particularly Simian crease have also been previously observed in apparently normal individuals in several populations, including Nigerians (20,21), Koreans (5),Central Indians (30) and Americans (4). Furthermore, some individuals with Simian crease were even described as exceptionally intelligent $(31,32)$. On the contrary, aberrant palmar creases are also known to be associated with many disease conditions as stated above (8,9,11-17).

Within the same population, the pattern of palmar creases may vary between the two sexes and sides. Indeed, in this study, remarkable differences were observed between females and males in relation to the prevalence of points of origin and presence of minor creases. Two pints of origin was the main type of commencement in all types of the creases, in both sexes and sides, with an overall prevalence of $77.3 \%$. This is consistent with other studies in different populations $(4,5,22)$. Furthermore, three points of origin occurred mainly in the non-variant crease type, with only a small number of occurrence in the Sydney and Suwon crease types. On the other hand, all palmar creases with one point of origin occurred only in the Simian crease type. It, therefore, appears that unlike the two and three points of origin, which are non-specific to a crease type, one point of origin may be an indicative of Simian crease as was also suggested by Mattisonet al. (4).

The reason for such association of points of origin with gender and sides is not certainly known. This may be related to the relatively stronger flexed grip in the males than females, and right than left palms. Indeed, Park et al. (5) suggest that palm creases with more united major creases and have fewer points of origin, may be more frequent on palms that are adapted for a stronger flexed grip.

In this study, RLC was found to have the most frequent variants, followed by PTC and then DTC. Accessory type of variant was the most frequent in the RLC and was more common on the right palms. This is in contrast to the study in the Korean population, where branched variant was the most prevalent in all the three major creases (5). Furthermore, a middle finger crease was seen as an additional minor variant with a total frequency of $9.1 \%$, and was more frequent on the right than the left palms. Middle finger crease was previously reported with variable prevalence among different Nigerian populations (21). Park et al. (5) consider that minor variant crease types appear more as compensation and for a uniform distribution of creases over the palm when the major crease types are less developed. In light with such an opinion, further quantitative studies may be required to investigate why the currently observed minor variants were more on the right than the left sides.

In conclusion, all types of palmar creases are present in the studied population. Furthermore, the various aberrant crease types detected may not be

DOI: http://dx.doi.org/10.4314/ejhs.v29i3.12 
indicative of known disease conditions at the observed frequencies, as they occurred in apparently healthy individuals. However, they may be associated with several factors such as ethnicity, gender, handedness, and levels of strength in palm flexion. Further systematic qualitative and quantitative studies of the configurations of palmar creases may, therefore, be needed in wider populations with different conditions. Nevertheless, the findings from this study, in addition to revealing the status of palmar creases among Ethiopians, could give a baseline for further studies aimed towards acquiring clues for diagnosis of disease conditions based on palmar crease configurations.

\section{ACKNOWLEDGMENTS}

I would like to extend my thanks to Prof Alemayehu Worku for the assistance he provided in sample size estimation as well as statistical analysis. My deepest gratitude also goes to the study participants, without whom this study would have been impossible.

\section{REFERENCES}

1. Milton A. Variation in Palm creases. $A m$ $J$ Dis Child, 1970; 120: 424-431.

2. Kava MP, Tullu MS, Muranjan MN, Girisha KM. Down syndrome: Clinical profile from India. Arch Med Res, 2004; 35(1):31-35.

3. Chaube R. Palm creases in population studies. Am J Physical Anthrop, 1977; 47:7-9.

4. Mattison, SM, Brunson EK, Holman DJ. Palm creases: classification, reliability and relationships to fetal alcohol spectrum disorders (FASD). Coll Antropol, 2015; 39(3):769-774.

5. Park JS, Shin DS, Jung W, Chung MS. Improved analysis of palm creases. Anat Cell B, 2010; 43 (2):169-177.

6. Purvis-Smith SG, Menser MA. Dermatoglyphics in adults with congenital rubella. Lancet, 1968; 1: 141143.

7. Johnson CF, Opitz E. The single palm crease and its clinical significance in a child development clinic: observations and correlations. Clinical Pediatrics, 1971; 10:392-403.

8. Dar H, Carney J, Winter ST. Dermatoglyphics and the Simian Crease in infants of low birth weight. Acta Poediatrica Scand, 1971; 60:479-481.

9. Lopuszanska M, Jankowska EA. Dermatoglyphic morphology in some diseases. Pol Merkur Lekarski, 2001; 11(63):282-286.

10. Tay JSH. The genetics of palmar creases. A study in the inheritance of liability estimated from the incidence among relatives. Ann Hum Genet, 1979; 42(3): 327-32.

11. Penrose LS. Fingerprint, Palm and chromosomes.Nature, 1963; 9:933 - 938.

12. Rignell A. Simian crease incidence and the correlation with thenar and hypothenar pattern types in Swedish patients with trisomy 21 (Down's syndrome). Am J Phys Anthropol, 1987; 72:277-286.

13. Hijmans JC, Shearin DB.Partial deletion of short arms of chromosome No.5.Am J Dis Child, 1965; 109:85-89.

14. Dar H, Winter ST. A study of Dermatoglyphics and the Simian Crease in familial deafness.Hum Hered, 1970; 20:493-506.

15. Dar H, Jaffe M. Dermatoglyphic and palm-crease alterations as indicators of early intra-uterine insult in mental retardation. Dev Med Child Neurol, 1983; 25: $53-59$

16. Lerer RJ. Do hyperactive children tend to have abnormal palm creases? Report of a suggestive association.Clin Pediatr, 1977; 16:645-647.

17. Jones KL, Robinson LK, Bakhireva LN, Marintcheva G, Storojev V, Strahova A, et al. Accuracy of the diagnosis of physical features of fetal alcohol syndrome by pediatricians after specialized training. Pediatrics, 2006; 118(6): e1734-1738

DOI: http://dx.doi.org/10.4314/ejhs.v29i3.12 
18. Shiono H. Dermatoglyphics in medicine. Am J Forensic Med Pathol, 1986; 7(2):120-126.

19. Caplan RM. How fingerprints came into use for personal identification. $J \mathrm{Am} \mathrm{Acad}$ Dermatol, 1990; 23(1):109-114.

20. Oyinbo C, Fawehinmi H. Prevalence of simian and Sydney creases in the Ijaws of South- South Nigeria. Internet $J$ Biol Anthrop, 2008; 3(2): 1-5.

21. Adetona MO, Oladapo OO, Akinyemi JO. Palm flexion creases variants among Nigerians. Afr J Biomed Res, 2012; 15(2): 93-96

22. Taura AA, Taura MG, Adamu LH. Palm Creases; A comparative study between epilepsy patients and healthy subjects among Hausas of Northern Nigeria. Am J Med and Med Sci, 2014; 4(5): 175-179

23. Alhaji MM, Timbuak J, Umana UE, Tanko M. Palm creases and handedness in Hausas of northern Nigeria: a crosssectional study. Asian $J$ Biol and Med Sci, 2015; 1(2): 6-13.

24. Excoffier L. Human demographic history: refining the recent African origin model. Curr Opin Genet Dev, 2002; 12(6): 675-682.

25. Tishkoff SA, Reed FA, Friedlaender FR, Ehret C, Ranciaro A, Froment A, et al. The genetic structure and history of Africans and African Americans, Science, 2009; 324: 1035-1044.

26. Campbell MC, Tishkoff SA. African genetic diversity: implications for human demographic history, modern human origins, and complex disease mapping. Annu Rev Genomics Hum Genet, 2008;9: 403-433.

27. Kitchen A, Ehret C, Assefa S, Mulligan CJ. Bayesian phylogenetic analysis of Semitic languages identifies an Early
Bronze Age origin of Semitic in the Near East, 2009; Proc Biol Sci, 276(1668): 2703-2710.

28. Naing L, Winn T, Rusli BN. Practical Issues in Calculating the Sample Size for Prevalence Studies. Arch Orofac Sci, 2006; 1: 9-14.

29. Stelin Wersely AM, Manjunath KY, Kumar KV, Vrijakumari CR. Photographic Method in Dermatoglyphics Analysis. IOSR J Dent and Med Sci, 2016; 15(12):1-3.

30. Sharma DK, Sharma V. Prevalence of Simian, Sydney and Suwon creases and their association with each other, body sides, handedness, sex and anomalies/diseases/syndromes in a population of Central India. Int. J. Morphol, 2011: 29(3):1069-1075.

31. LdeLstrange MT. The transverse crease in Europe: Index and comparative study of different samples cited in the literature. Am J Phys Anthropol, 1969; 30(2)173182.

32. Hernández M. Palmar creases in Spaniards. Anthropol Anz, 1985; 43(2):187- 190.

33. Dar H, Schmidt R, Nitowsky HM. Palm crease variants and their clinical significance: a study of newborns at risk. Pediatric Res, 1977; 11:103-108.

34. Arrieta MI, Martinez B, Simon A, Salazar L, Criado B, Lostao CM. Quantitative and qualitative finger Dermatoglyphics in the Basque Valley of Urola, Spain. Anthropol Anz,1990; 48(1):65-84.

35. Arrieta MI, Criado B, Martinez B, Lobato MN, Gil A, Lostao C M. Fluctuating Dermatoglyphic asymmetry: genetic and prenatal influences. Ann Hum Biol, 1993; 20(6):557-563. 